\title{
The Optimization of $J_{c}, B_{\text {irr }} n$ value, Wires Diameter, and Research of the Dominant Pinning Mechanism for Applications of Undoped $\mathrm{MgB}_{2}$ in Superconducting Multi-section Coils
}

\author{
D. Gajda ${ }^{1} \cdot$ A. J. Zaleski ${ }^{1} \cdot$ A. Morawski ${ }^{2} \cdot$ T. Cetner $^{2} \cdot$ M. Małecka $^{1} \cdot$ M. Rindfleisch ${ }^{3}$
}

Received: 16 July 2020 / Accepted: 28 August 2020 / Published online: 8 September 2020

(C) The Author(s) 2020

\begin{abstract}
This article discusses the influence of $\mathrm{MgB}_{2}$ wire diameter on critical parameters, dominant pinning mechanism, and $n$ value. Studies were conducted on multifilament $\mathrm{MgB}_{2}$ wires of the $0.84 \mathrm{~mm}$ and $0.64 \mathrm{~mm}$ diameter. The wires were annealed under $1 \mathrm{GPa}$ isostatic pressure, between 650 and $730{ }^{\circ} \mathrm{C}$. Studies show that the best results $\left(J_{\mathrm{c}}, B_{\text {irr }}, n\right.$ value, and point pinning mechanism) for a $0.64-\mathrm{mm}$ wire were obtained with annealing temperature of $650{ }^{\circ} \mathrm{C}$. However, the best results for wires with a $0.84-\mathrm{mm}$ diameter were obtained with annealing temperature of $730^{\circ} \mathrm{C}$. This research was conducted for exploring the use of $\mathrm{MgB}_{2}$ wires in multi-section superconducting coils, e.g., main coils generating magnetic fields and compensation coilsincreasing the homogeneity of the magnetic field. Our research indicates that the main coil made with larger diameter wires should be heated at higher temperature $\left(730^{\circ} \mathrm{C}\right)$. In contrast, compensating coils with smaller diameter wires should be heated at a lower temperature $\left(650^{\circ} \mathrm{C}\right)$.
\end{abstract}

Keywords Critical current density $\cdot n$ value $\cdot$ Irreversible magnetic field

\section{Introduction}

Research presented by Uchiyama et al. [1], Wang et al. [2], and Gajda et al. [3] showed that the reduction of the diameter of a superconductor wire as the result of cold drawing led to an increase of critical current density, irreversible magnetic field, pinning force, $n$ value, and dominant pinning mechanism for samples heat treated at a constant temperature, due to increased $\mathrm{MgB}_{2}$ density, $\mathrm{Mg}$ elongation, formation of a layered structure, and increased density of pinning centers [1-5]. In contrast, $\mathrm{Xu}$ et al. indicated that a significant reduction of wire diameter causes a decrease of $J_{\mathrm{c}}$ [6]. The critical current density, irreversible magnetic field, and dominant pinning

D. Gajda

d.gajda@intibs.pl

1 Institute of Low Temperature and Structure Research PAS, Okólna 2, 50-422 Wroclaw, Poland

2 Institute of High Pressure Physics PAS, Unipress, Sokołowska 29/37, 01-142 Warszawa, Poland

3 Hyper Tech Research, Inc., 539 Industrial Mile Road, Columbus, OH 43228, USA mechanism in $\mathrm{MgB}_{2}$ material depend on many factors, e.g., connections between grains, nano-additives $[7,8]$, the purity of the starting materials $[9,10]$, milling time [9-11], type of pinning centers [12-14], heat treatment temperature [15], defects, pores, and voids [16]. The $n$ value, which qualifies the transition from the superconducting state to the normal state, is an important factor that influences the selection of the operating current for a superconducting device, coil, magnet, etc. [17]. The $n$ value of a superconductor has a dependency on both intrinsic (connections between grains, grain microstructure, pinning centers) and extrinsic (filament distribution and quantity) $[18,19]$ factors. Superconducting applications include magnetic resonance imaging (MRI), induction furnace, magnetic separation, energy storage, laboratory magnets, and the International Thermonuclear Experimental Reactor. Many of these applications such as MRI require the generation of magnetic fields with high homogeneity produced from the superconductor coil. Unfortunately, superconducting coils have a large magnetic field gradient (difference in magnetic field between the magnet center and the magnet end). This disadvantage is eliminated by external compensating windings, which are coils that significantly increase the homogeneity of the magnetic field in the magnet. Compensation windings are made with superconductor wires of smaller diameter 
than the superconductor wires used in the main coil windings. Traditional superconducting magnets in the past were made using reacted superconducting wires (superconductive phase). More often today, coils are made with using unreacted wires and tapes such that the superconducting phase will be produced after the wire is wound on the coil former. This method eliminates cracks (e.g., damage to connections between inbound, $\mathrm{Nb}$ barriers) which it might occur during winding the coil. One crack significantly reduces $J_{\mathrm{c}}$ and hinders the use of the superconducting coil. Usually, the superconductor coils are made of several kilometers of superconducting wires. Based on superconductivity characterization and scanning microscope electron (SEM) analyses, small coil (diameter $14 \mathrm{~mm}$ ) wounds with unreacted $\mathrm{MgB}_{2}$ wires have obtained high critical current density when annealed under high isostatic pressure of $1 \mathrm{GPa}$. In addition, Gajda et al. showed that the HIP process can be applied to small coils with no loss in superconductivity properties as compared with short samples [20]. The HIP process has been demonstrated to improve homogeneity and density of $\mathrm{MgB}_{2}$; reduce pore size, grains, and voids; improve the connection between grains; create pinning centers with homogeneous distribution; and increase the melting point in wires [21-24]. Moreover, Gajda et al. demonstrated that high isostatic pressure of $1 \mathrm{GPa}$ significantly increased $J_{\mathrm{c}}$ in high magnetic fields [3].

This research was conducted to determine the impact of $\mathrm{MgB}_{2}$ wire diameter and high isostatic pressure heat treatment on $J_{\mathrm{c}}, B_{\text {irr }}, n$ value, $F_{\mathrm{p}}$, dominant pinning mechanism, and $\mathrm{MgB}_{2}$ material structure. The goal was to identify the optimal heat treatment protocol for the production of multi-sectional superconducting $\mathrm{MgB}_{2}$ coils.

\section{Preparation of Samples}

The in situ $\mathrm{MgB}_{2}$ wires were made of powders with purity of 99\% (the nominal atomic ratio 1.10:2) and average boron and magnesium powder size of $50 \mathrm{~nm}$ and $40 \mu \mathrm{m}$. The filaments are made with continuous tube forming and filling (CTFF) method and restacked as a 18 -filament wire at Hyper Tech Research, Inc. [25]. The wire compositions were $\mathrm{Nb}$ chemical barrier, $\mathrm{Cu}$ filamentary matrix, and Monel outer sheath; the fill factor was $15 \%$, and the wires were drawn to 0.64 and $0.84 \mathrm{~mm}$. The wires of both sizes were heat treated together at the same temperature (from 650 to $730{ }^{\circ} \mathrm{C}$ ), pressure $(1 \mathrm{GPa}$ ), and time (from 15 to $60 \mathrm{~min}$ ) at the Institute of High Pressure Physics in Warsaw (see Table 1) [26, 27]. Critical current measurements were made at the Institute of Low Temperature and Structure Research PAS in Wroclaw, with a four-probe resistive method. All samples were measured in a perpendicular magnetic field (Bitter-type magnet-14 T) at liquid helium temperature, with constant current, and in accordance with a $1 \mu \mathrm{V} / \mathrm{cm}$ criterion [28]. Sample length was $20 \mathrm{~mm}$. Kramer analysis used the $J_{\mathrm{c}}^{0.5 *} B^{0.25}$ formula [29]; scaling used the $k^{*}\left(h^{\mathrm{p}}\right)^{*}(1-h)^{\mathrm{q}}$ formula [30]. Analysis of the microstructure and composition were performed by FEI Nova Nano 230 SEM at the Institute of Structural Research and Low Temperatures PAS in Wroclaw.

\section{SEM Analysis}

The results in Fig. 1 show the cross (Fig. 1a, b, e, f) and longitudinal (Fig. 1i and j) sections for sample A and B. Sample B has better connection between particles than sample A. In sample B, the small number of small-sized voids is created. In Fig. 1 we see cross (Fig. 1c, d, g, h) and longitudinal (Fig. 1k and 1 ) sections for sample $\mathrm{G}$ and $\mathrm{H}$. These photos indicate the larger and more voids are formed in sample $\mathrm{H}$ compared with sample G. This leads to the reduction of the density, homogeneity, and number of grains connections in the sample H. This leads to the reduction of the transport critical parameters in the superconducting materials. Based on the results in Fig. 1, it can be concluded that the synthesis reaction is faster in the of $0.64-\mathrm{mm}$-diameter wires than $0.84 \mathrm{~mm}$ diameter wires. The $\mathrm{MgB}_{2}$ wires of the $0.64 \mathrm{~mm}$ diameter are obtained with the $\mathrm{MgB}_{2}$ wires of $0.84 \mathrm{~mm}$ diameter by using cold drawing. Susner et al. showed that cold drawing causes elongates and reduces the thickness of $\mathrm{Mg}$ grains [5]. This leads to the faster synthesis reaction rate in $\mathrm{MgB}_{2}$ wires of the $0.64 \mathrm{~mm}$ diameter.

\section{Results and Discussions}

\subsection{Annealing Temperature $\left(T_{\mathrm{a}}\right)$ of $650^{\circ} \mathrm{C}$ for $60 \mathrm{~min}$}

The measurements and calculations indicate that a reduction of the $\mathrm{MgB}_{2}$ wire diameter from 0.84 to $0.64 \mathrm{~mm}$ significantly increases $J_{\mathrm{c}}$ in sample B $\left(1000 \mathrm{~A} / \mathrm{mm}^{2}\right.$ in $6.3 \mathrm{~T}$ and $100 \mathrm{~A} /$ $\mathrm{mm}^{2}$ in $\left.10 \mathrm{~T}\right)$ as compared with sample $\mathrm{A}\left(1000 \mathrm{~A} / \mathrm{mm}^{2}\right.$ in $5 \mathrm{~T}$ and $100 \mathrm{~A} / \mathrm{mm}^{2}$ in $8.5 \mathrm{~T}$ ). The $J_{\mathrm{c}}$ of sample B overall is $50 \%$ higher than $J_{\mathrm{c}}$ sample A (Fig. 2a). Comparing these results (sample B) with the results of Li et al. [31] and Yamada et al. [32], our undoped $\mathrm{MgB}_{2}$ wires have higher $J_{\mathrm{c}}$ than undoped $\mathrm{MgB}_{2}$ wires studies by others $\left(1000 \mathrm{~A} / \mathrm{mm}^{2}\right.$ in $3 \mathrm{~T}$ and $100 \mathrm{~A} / \mathrm{mm}^{2}$ in $6.2 \mathrm{~T}$-annealing temperature of $675^{\circ} \mathrm{C}$ ) [31] and tapes $\left(500 \mathrm{~A} / \mathrm{mm}^{2}\right.$ in $7 \mathrm{~T}$ and $100 \mathrm{~A} / \mathrm{mm}^{2}$ in $9.5 \mathrm{~T}$ annealing temperature of $\left.630^{\circ} \mathrm{C}\right)$ [32]. The maximum pinning force $\left(F_{\text {pmax }}\right)$ is in $4 \mathrm{~T}\left(6400 \mathrm{MN} / \mathrm{m}^{3}\right)$ for sample A and $5 \mathrm{~T}$ $\left(8700 \mathrm{MN} / \mathrm{m}^{3}\right)$ for sample A, Fig. $2 \mathrm{~b}$. The $5 \mathrm{~T} F_{\text {pmax }}$ is a good result for undoped $\mathrm{MgB}_{2}$ wires. Based on Kramer [29], the irreversible magnetic field $\left(B_{\text {irr }}\right)$ was $15.2 \mathrm{~T}$ for sample $\mathrm{A}$ and 16.3 T for sample B (Fig. 3). Analysis of Dew-Hughes in Fig. 4 shows that for sample $\mathrm{A}, F_{\mathrm{p}} / F_{\mathrm{pmax}}$ equals 1 is in $B /$ $B_{\text {irr }}=0.27$, meaning that point dominant pinning mechanism 
Table 1 Samples table and the HIP process parameters

\begin{tabular}{lllll}
\hline No. & \multicolumn{2}{l}{ Annealing time, temperature, and pressure-HIP process } & $\begin{array}{l}\text { Diameter of the wires } \\
(\mathrm{mm})\end{array}$ \\
\cline { 2 - 4 } & $(\mathrm{min})$ & $\left({ }^{\circ} \mathrm{C}\right)$ & $(\mathrm{Pa})$ & \\
\hline $\mathrm{A}$ & 60 & 650 & $1 \mathrm{G}$ & 0.84 \\
$\mathrm{~B}$ & 60 & 650 & $1 \mathrm{G}$ & 0.64 \\
$\mathrm{C}$ & 15 & 680 & $1 \mathrm{G}$ & 0.84 \\
$\mathrm{D}$ & 15 & 680 & $1 \mathrm{G}$ & 0.64 \\
$\mathrm{E}$ & 15 & 700 & $1 \mathrm{G}$ & 0.84 \\
$\mathrm{~F}$ & 15 & 700 & $1 \mathrm{G}$ & 0.64 \\
$\mathrm{G}$ & 15 & 730 & $1 \mathrm{G}$ & 0.84 \\
$\mathrm{H}$ & 15 & 730 & $1 \mathrm{G}$ & 0.64 \\
$\mathrm{I}$ & 60 & 700 & $1 \mathrm{G}$ & 0.84 \\
$\mathrm{~J}$ & 60 & 700 & $1 \mathrm{G}$ & 0.64 \\
\hline
\end{tabular}

is in ranges from 0 to 0.27 , shifting first to surface pinning and then to volume above 0.27 . For sample $\mathrm{B}, F_{\mathrm{p}} / F_{\text {pmax }}$ equals 1 is in $B / B_{\text {irr }}=0.32$ (Fig. 4 ), showing that point dominant pinning mechanism is in ranges from 0 to 0.32 and above 0.32 dominant pinning mechanism shifts first to surface and then to volume. Based on SEM images (Fig. 1), we can conclude that
$\mathrm{Mg}$ grains of smaller thickness correspond to higher $J_{\mathrm{c}}$ for reaction heat treatments at low temperatures $\left(650^{\circ} \mathrm{C}\right)$.

Critical current density, magnetic field dependency, and $n$ value all are important parameters of a superconductor for the design of coil or magnet using them. The $n$ value parameter describes the quality of the transition of the superconducting
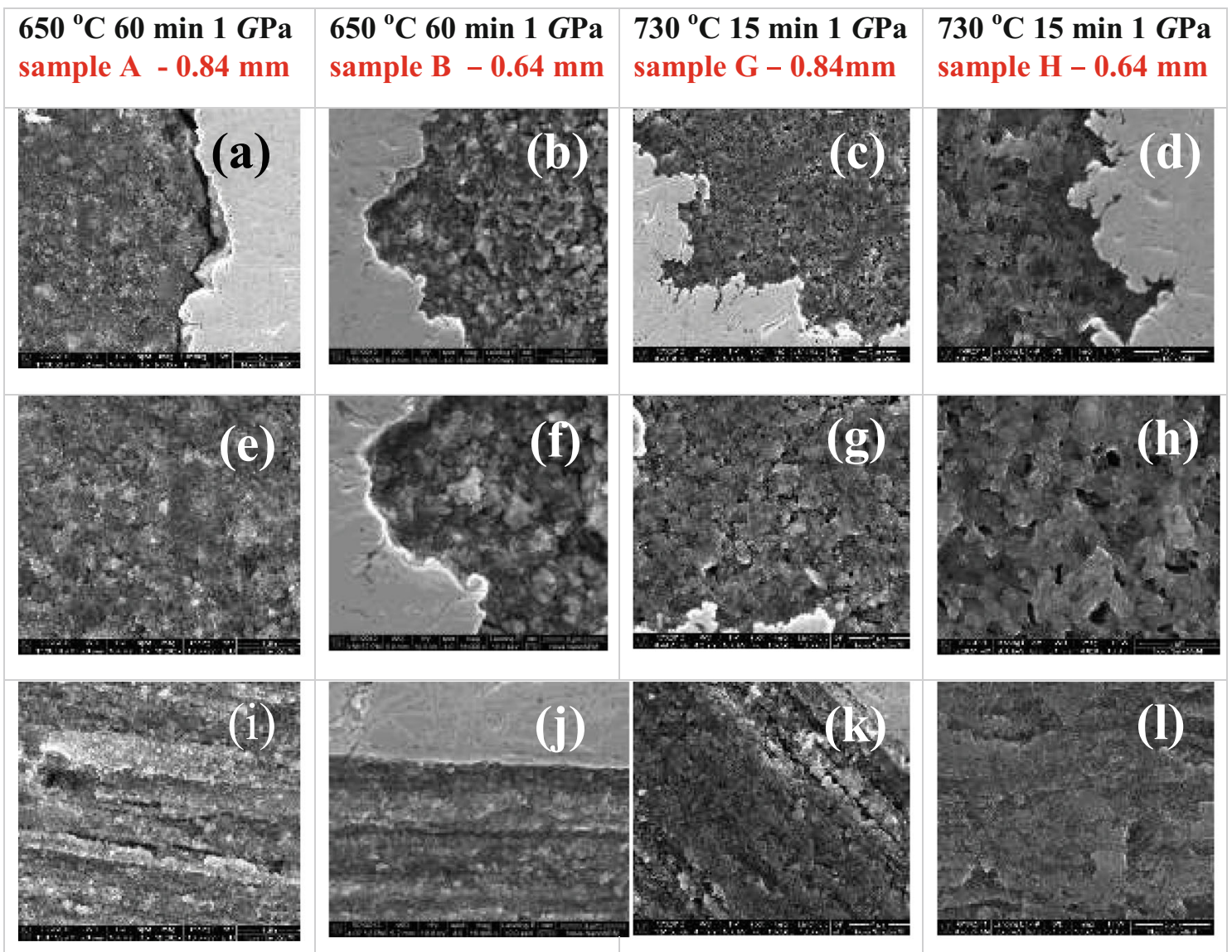

Fig. 1 The effects of wire diameter and annealing temperature on the microstructure of the wires samples obtained by HIP at $1 \mathrm{GPa}$ pressure for eighteen filaments $\mathrm{MgB}_{2}$ wires, with $\mathrm{Nb}$ barrier, copper matrix, and
Monel outer sheath. The SEM images of the microstructure were taken in SE mode: (a) - (h) transverse cross-section; (i) - (l) longitudinal section 
Fig. 2 a Transport $J_{\mathrm{c}}-B$ curves for undoped $\mathrm{MgB}_{2}$ wires in perpendicular magnetic field and b the pinning force density $F_{\mathrm{p}}$ as function of perpendicular magnetic field for undoped $\mathrm{MgB}_{2}$ wires

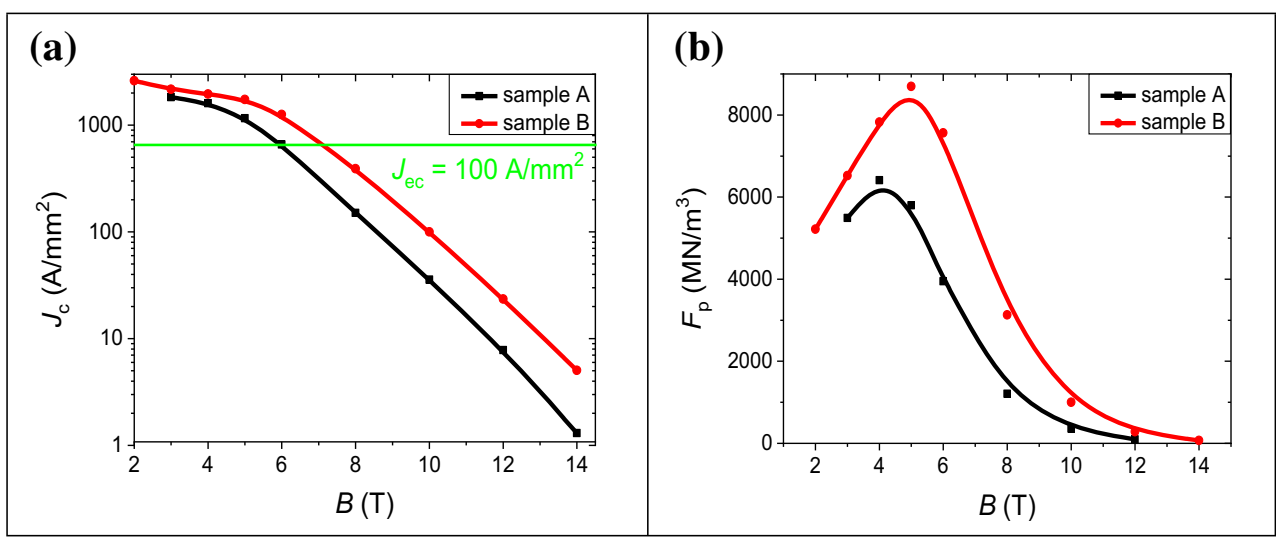

material from the superconducting state to the resistive state. In addition, $n$ value influences the selection of the operating current for designing a superconducting coil [17]. In this paper, engineering critical current density $\left(J_{\mathrm{ec}}\right)$ is the critical current density $\left(J_{\mathrm{c}}\right)$ divided by the cross-sectional area of the wire. Currently, applications of superconducting wire should have the engineering critical current density of about $100 \mathrm{~A} /$ $\mathrm{mm}^{2}$ and $n$ value of 20 [17]. Measured $n$ values for sample A and B is shown in Fig. 5. Sample A annealed at $650{ }^{\circ} \mathrm{C}$ for 60 min with $1 \mathrm{GPa}$ pressure obtained an $n$ value of 20 and $J_{\mathrm{c}}$ of $1600 \mathrm{~A} / \mathrm{mm}^{2}\left(240 \mathrm{~A} / \mathrm{mm}^{2} J_{\text {ec }}\right)$ at $4 \mathrm{~T}$; sample B annealed with the same parameters had a $n$ value of 20 and $J_{\mathrm{c}}$ of $1260 \mathrm{~A} / \mathrm{mm}^{2}$ $\left(J_{\mathrm{ec}}-318 \mathrm{~A} / \mathrm{mm}^{2} J_{\mathrm{e}}\right)$ at $6 \mathrm{~T}$. Parizh et al. indicated that for $n$ value of 20 , the operating current of a superconducting coil would be set to $50 \%$ of the critical current [17].

Figure 5 shows the dependencies of $n$ value with both current density $J_{\mathrm{c}}$ and applied field $B$. The relationship between $n$ value and $B$ indicates that the reduction of the $\mathrm{MgB}_{2}$ wire diameter significantly increases $n$ value in low and middle magnetic fields. It should be recalled that critical current density depends on pinning center density and that the pinning centers are activated by the external magnetic field

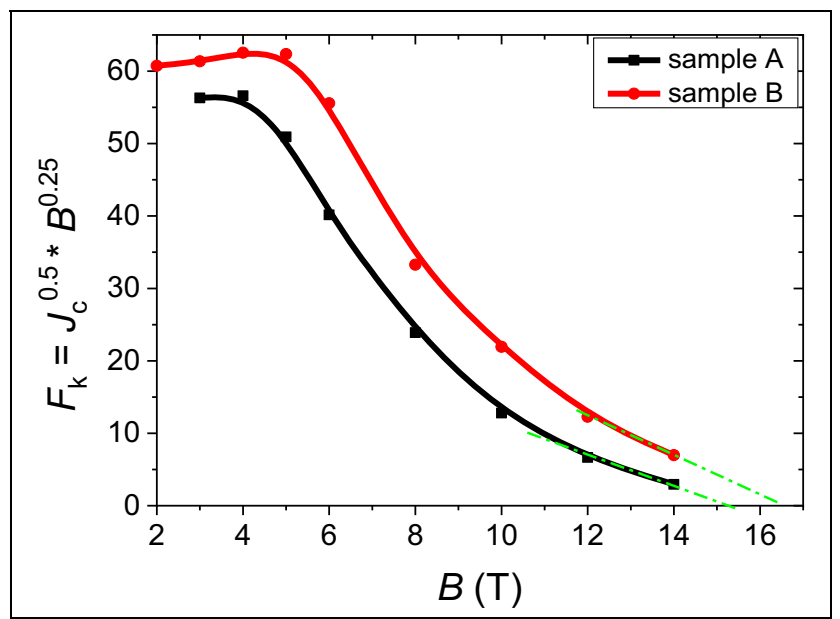

Fig. 3 The change of $J^{0.5} B^{0.25}$ as a function of perpendicular to the wire axis magnetic field, for the $0.84-\mathrm{mm}$ and 0.64 -diameter-mm wires
[14]. Gajda et al. indicated that different types of pinning centers strongly pin the vortex lattice in different ranges of magnetic field [33]. Calculations carried out using the CMF [34] method for sample B with an $n$ value of 20 indicate that the $B / B_{\text {irr }}(6 \mathrm{~T} / 16.5 \mathrm{~T})$ coefficient is 0.36 . This $B / B_{\text {irr }}$ coefficient value indicates dominant point pinning centers. On the other hand, calculations for sample $C$ show that the $B / B_{\text {irr }}$ coefficient is 0.26 for an $n$ value of 20, meaning that dominant mechanism is surface pinning. Dew-Hughes analysis shows that the reduction of the wire diameter leads to the change of the dominant pinning mechanism. On this basis, it can be deduced that the $n$ value increase in a $\mathrm{MgB}_{2}$ wire with sized to $0.64 \mathrm{~mm}$ was a result of a high density of point pinning centers being obtained.

The $n$ value- $J_{\mathrm{c}}$ relationship indicates that the reduction of the $\mathrm{MgB}_{2}$ wire diameter does not influence $n$ value. This indicates that the same pinning force $\left(F_{\mathrm{p}}\right)$ is present in both samples A and B. However, Dew-Hughes, SEM, and CMF analysis [34] indicate that the $J_{\mathrm{c}}$ in sample B was created by

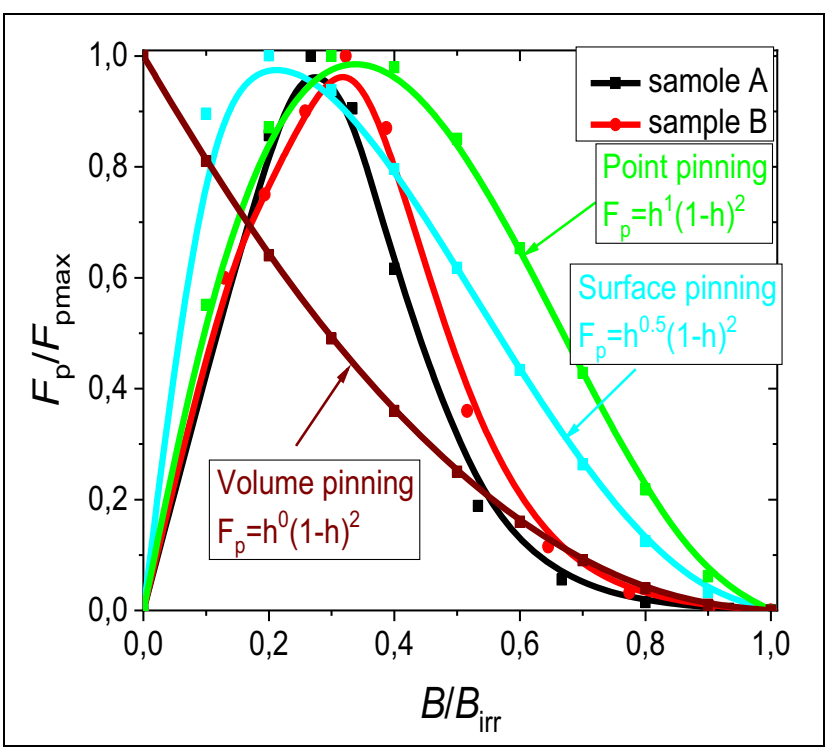

Fig. 4 The reduced pinning force density as a function of perpendicular to the wires axis magnetic field, for undoped $\mathrm{MgB}_{2}$ wires 


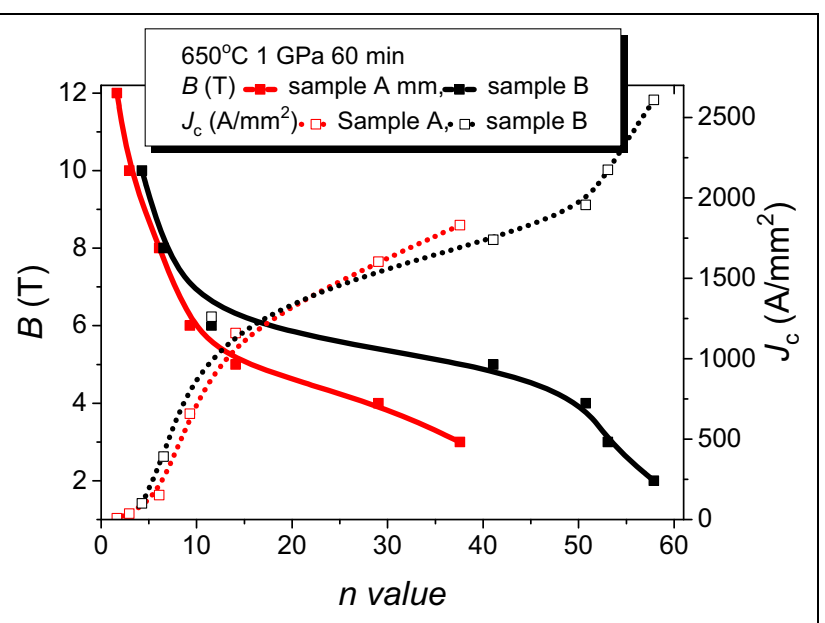

Fig. 5 The $n$ value dependence of the two specified wires diameters obtained for the perpendicular to the wires axis magnetic field in undoped $\mathrm{MgB}_{2}$ wires

mainly pinning point centers. On the other hand, the $J_{\mathrm{c}}$ in sample A was formed by mainly surface pinning centers. This difference can only be determined when analyzing $n$ value and $J_{\mathrm{c}}$ in relation to the magnetic field.

\subsection{Annealing Temperature $\left(T_{a}\right)$ from 680 to $730^{\circ} \mathrm{C}$ by $15 \mathrm{~min}$}

Figure $6 \mathrm{a}, \mathrm{c}$, and e show that an increase of annealing temperature from 680 to $730{ }^{\circ} \mathrm{C}$ in $\mathrm{MgB}_{2}$ wires with a $0.84 \mathrm{~mm}$ diameter increases $J_{\mathrm{c}}$ by $50 \%$. SEM results in Fig. 1 indicate that the higher annealing temperature $\left(730^{\circ} \mathrm{C}\right)$ of undoped $\mathrm{MgB}_{2}$ wires with a diameter of $0.84 \mathrm{~mm}$ produces a greater number of big and small voids (point and surface pinning centers) and increases the number of connections between grains. Therefore, the $J_{\mathrm{c}}$ for 0.84 -mm-undoped $\mathrm{MgB}_{2}$ wires increases with increased annealing temperature. On the other hand, increasing the annealing temperature from 680 to $700{ }^{\circ} \mathrm{C}$ in $0.64-\mathrm{mm} \mathrm{MgB}_{2}$ wires reduces $J_{\mathrm{c}}$ by $40 \%$. Increasing the annealing temperature further to $730{ }^{\circ} \mathrm{C}$ decreases $J_{\mathrm{c}}$ by $25 \%$ between 2 and $8 \mathrm{~T}$ and increases $J_{\mathrm{c}}$ by $25 \%$ above $8 \mathrm{~T}$ (Fig. 7). SEM pictures show that annealing at $730{ }^{\circ} \mathrm{C}$ of wires with a $0.64 \mathrm{~mm}$ diameter creates big voids, creating surface pinning centers and reducing the number of connections between grains, leading to a decrease in $J_{\mathrm{c}}$. The improvement of $J_{\mathrm{c}}$ above $8 \mathrm{~T}$ in sample $\mathrm{H}$ indicates that the annealing temperature of $730^{\circ} \mathrm{C}$ led to formation of high-field pinning centers, creating dislocations and strains. At $730{ }^{\circ} \mathrm{C}$ and $1 \mathrm{GPa}, \mathrm{Mg}$ is in a liquid state and $\mathrm{B}$ solid state. Large voids (Fig. 1) and strains (dislocations) are created, while $\mathrm{Mg}$ is in the liquid state. Increasing annealing from 680 to $730{ }^{\circ} \mathrm{C}$ for $0.84-\mathrm{mm}$ wires significantly increases $F_{\mathrm{p}}$ in low and middle magnetic fields (Fig. 6b, d, and f), suggesting that the higher annealing temperature increased the number of surface and point pinning centers. In Fig. 6b, d, and f, increasing annealing from 680 to $730{ }^{\circ} \mathrm{C}$ for 0.64 -mm wires significantly decreases $F_{\mathrm{p}}$ in low and middle magnetic fields and shifts $F_{\text {pmax }}$ from 4 to $2.5 \mathrm{~T}$, suggesting that the higher annealing temperature decreased the number of point pinning centers. The Kramer analysis [29] showed that increasing annealing from 680 to $730{ }^{\circ} \mathrm{C}$ in 0.84 -mm wires increases $B_{\text {irr }}$ from 15.9 to $16.3 \mathrm{~T}$ and decreases $B_{\text {irr }}$ from 16.5 to $15.2 \mathrm{~T}$ in $0.64-\mathrm{mm}$ wires. The $B_{\text {irr }}$ depends on the type and density of high-field pinning centers. In superconducting material, there are three types of high-field pining centers, e.g., dislocations, strains (e.g., substitution for $\mathrm{C}$ by B), and intra-grain precipitation [14]. Serquis et al. [21] showed that HIP process formed dislocations. This indicates that in our undoped $\mathrm{MgB}_{2}$ wires thermally treated under $1 \mathrm{GPa}$ isostatic pressure, it mainly forms high-field pinning centers. On this basis, we can indicate that increase of the annealing temperature from 680 to $730^{\circ} \mathrm{C}$ and the isostatic pressure of $1 \mathrm{GPa}$ allows to increase the density of high-field pinning centers in undoped $\mathrm{MgB}_{2}$ wires of $0.84 \mathrm{~mm}$ diameter. However, an increase of the annealing temperature and the isostatic pressure of $1 \mathrm{GPa}$ leads to a decrease in the density of high-field pinning centers in undoped $\mathrm{MgB}_{2}$ wires of the $0.64 \mathrm{~mm}$ diameter.

This same increase of annealing temperature for $0.64-\mathrm{mm}$ wires causes a shift of maximum ratio $F_{\mathrm{p}} / F_{\mathrm{pmax}}=1$ from $B /$ $B_{\text {irr }}=0.25\left(680^{\circ} \mathrm{C}\right)$ to $0.16\left(730^{\circ} \mathrm{C}\right)$ (Fig. 8$)$, indicating that the increase of annealing temperature changes the dominant pinning mechanism from surface to volume (big voids) (Fig. 1). Our calculations and extrapolations for 0.84-mm-undoped $\mathrm{MgB}_{2}$ wire shows that these wires also have the surface dominant pinning mechanism. A longer annealing time (60 min), $700{ }^{\circ} \mathrm{C}$ annealing temperature, and $1 \mathrm{GPa}$ isostatic pressure reduces $J_{\mathrm{c}}$ (e.g., $100 \mathrm{~A} / \mathrm{mm}^{2}$ at $8.8 \mathrm{~T}$ for $0.84-\mathrm{mm}$ wire and $100 \mathrm{~A} / \mathrm{mm}^{2}$ at $7.2 \mathrm{~T}$ for $0.64 \mathrm{~mm}$ ) (Fig. 9). Therefore, further studies with longer annealing time (e.g., $60 \mathrm{~min}$ ) were not conducted for $700{ }^{\circ} \mathrm{C}$ and $1 \mathrm{GPa}$ isostatic pressure.

The dependency of $n$ value with $B$ in Fig. 10 shows that increasing the annealing temperature from 700 to $730{ }^{\circ} \mathrm{C}$ for 0.84-mm-undoped $\mathrm{MgB}_{2}$ wires $n$ value increases, e.g., to 30 at $700{ }^{\circ} \mathrm{C}, 5 \mathrm{~T}$ and $1129 \mathrm{~A} / \mathrm{mm}^{2}\left(J_{\mathrm{ec}}-170 \mathrm{~A} / \mathrm{mm}^{2}\right)$, and to 45 at $730{ }^{\circ} \mathrm{C}, 5 \mathrm{~T}$ and $1407 \mathrm{~A} / \mathrm{mm}^{2}\left(J_{\text {ec }}-211 \mathrm{~A} / \mathrm{mm}^{2}\right)$. The results for sample $\mathrm{F}(0.64 \mathrm{~mm})$ show that higher annealing temperature corresponded to a low $n$ value (of 9 at $5 \mathrm{~T}$ and $750 \mathrm{~A} / \mathrm{mm}^{2}$ $\left.\left(J_{\mathrm{ec}}-100 \mathrm{~A} / \mathrm{mm}^{2}\right)\right)$, indicating that wire diameter reduction, high annealing temperature, and $1 \mathrm{GPa}$ high isostatic pressure significantly reduces $n$ value. In Fig. 10 we see the reduction of wire diameter and high annealing temperature $\left(700{ }^{\circ} \mathrm{C}\right)$ significantly reduces $n$ value, e.g., sample $\mathrm{E}$ has $n$ value of 50 at $1700 \mathrm{~A} / \mathrm{mm}^{2} J_{\mathrm{c}}$, and sample $\mathrm{F}$ has $n$ value of 20 at $1700 \mathrm{~A} / \mathrm{mm}^{2} J_{\mathrm{c}}$. On the other hand, higher annealing temperature for $0.84-\mathrm{mm}$ wires increases the $n$ value, e.g., sample $\mathrm{G}$ has $n$ value of 28 at $1000 \mathrm{~A} / \mathrm{mm}^{2} J_{\mathrm{c}}\left(150 \mathrm{~A} / \mathrm{mm}^{2} J_{\mathrm{ec}}\right)$ and sample $\mathrm{G}$ has $n$ value of 35 at $1000 \mathrm{~A} / \mathrm{mm}^{2} J_{\mathrm{c}}$. Previously results indicated that $J_{\mathrm{c}}$ is dependent on the density of the 
Fig. 6 Transport $J_{\mathrm{c}}-B$ curves for undoped $\mathrm{MgB}_{2}$ wires in perpendicular magnetic field (a) annealing temperature $\left(T_{\mathrm{a}}\right)$ of $680^{\circ} \mathrm{C}$, (c) $T_{\mathrm{a}}$ of $700{ }^{\circ} \mathrm{C}$, and (e) $T_{\mathrm{a}}$ of $730^{\circ} \mathrm{C}$. The pinning force density $F_{\mathrm{p}}$ as function of perpendicular magnetic field for undoped $\mathrm{MgB}_{2}$ wires (b) $T_{\mathrm{a}}$ of $680^{\circ} \mathrm{C}$, (d) $T_{\mathrm{a}}$ of $700^{\circ} \mathrm{C}$, and (f) $T_{\mathrm{a}}$ of $730^{\circ} \mathrm{C}$

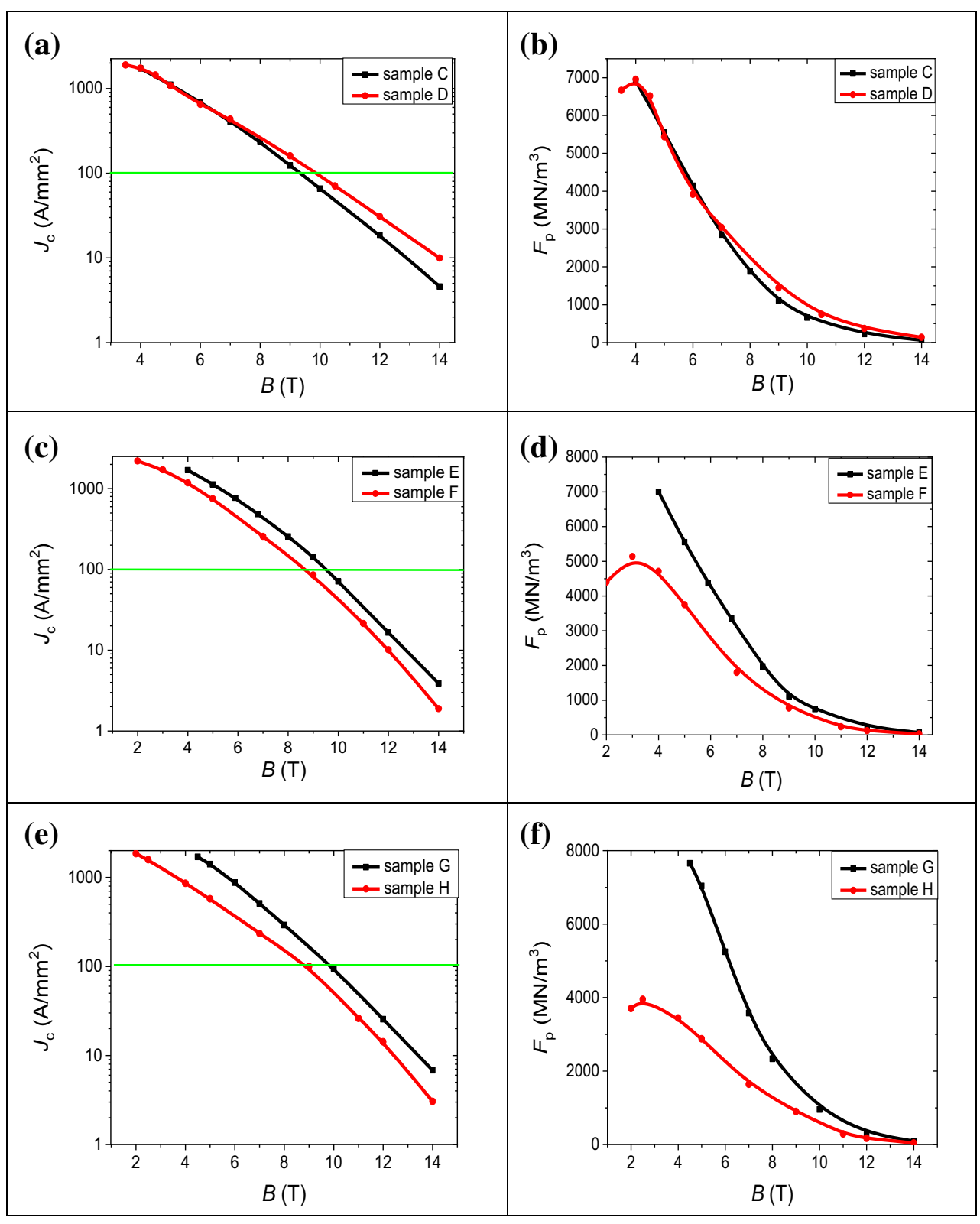

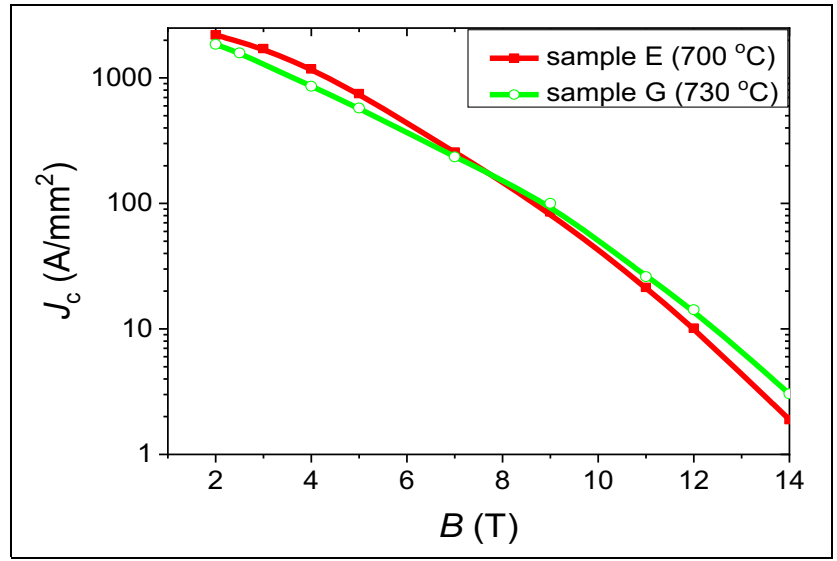

Fig. 7 Transport $J_{\mathrm{c}}-B$ curves for undoped $\mathrm{MgB}_{2}$ wires $(0.84 \mathrm{~mm}$ in perpendicular magnetic field pinning centers and that the pinning centers activate the external magnetic field [14]. Based on these assumptions, DewHughes analysis and CMF method [34], it can be concluded that increasing the annealing temperature from 680 to $730{ }^{\circ} \mathrm{C}$ for $0.64-\mathrm{mm}$ wires increases the surface pinning centers density and decreases the point pinning centers density, e.g., sample $\mathrm{F}$ with an $n$ value of 20 has a $B / B_{\text {irr }}$ coefficient $(3 \mathrm{~T} / 15 \mathrm{~T})$ of 0.2 - this value indicates surface pinning [34], leading to a reduction of $J_{\mathrm{c}}$ and $n$ value. For 0.84-mm wire samples, increasing the annealing temperature creates a higher density of point pinning centers, e.g., sample $\mathrm{E}$ has $B / B_{\text {irr }}$ coefficient of 0.38 with an $n$ value of 20 - this value indicates point pinning centers, which correspondingly increases $J_{\mathrm{c}}$ and $n$ value. 
Fig. 8 The reduced pinning force density as a function of perpendicular to the wires axis magnetic field, for undoped $\mathrm{MgB}_{2}$ wires (a) $T_{\mathrm{a}}$ of $680^{\circ} \mathrm{C},(\mathbf{b})$ $T_{\mathrm{a}}$ of $700^{\circ} \mathrm{C}$, and $(\mathbf{c}) T_{\mathrm{a}}$ of $730^{\circ} \mathrm{C}$

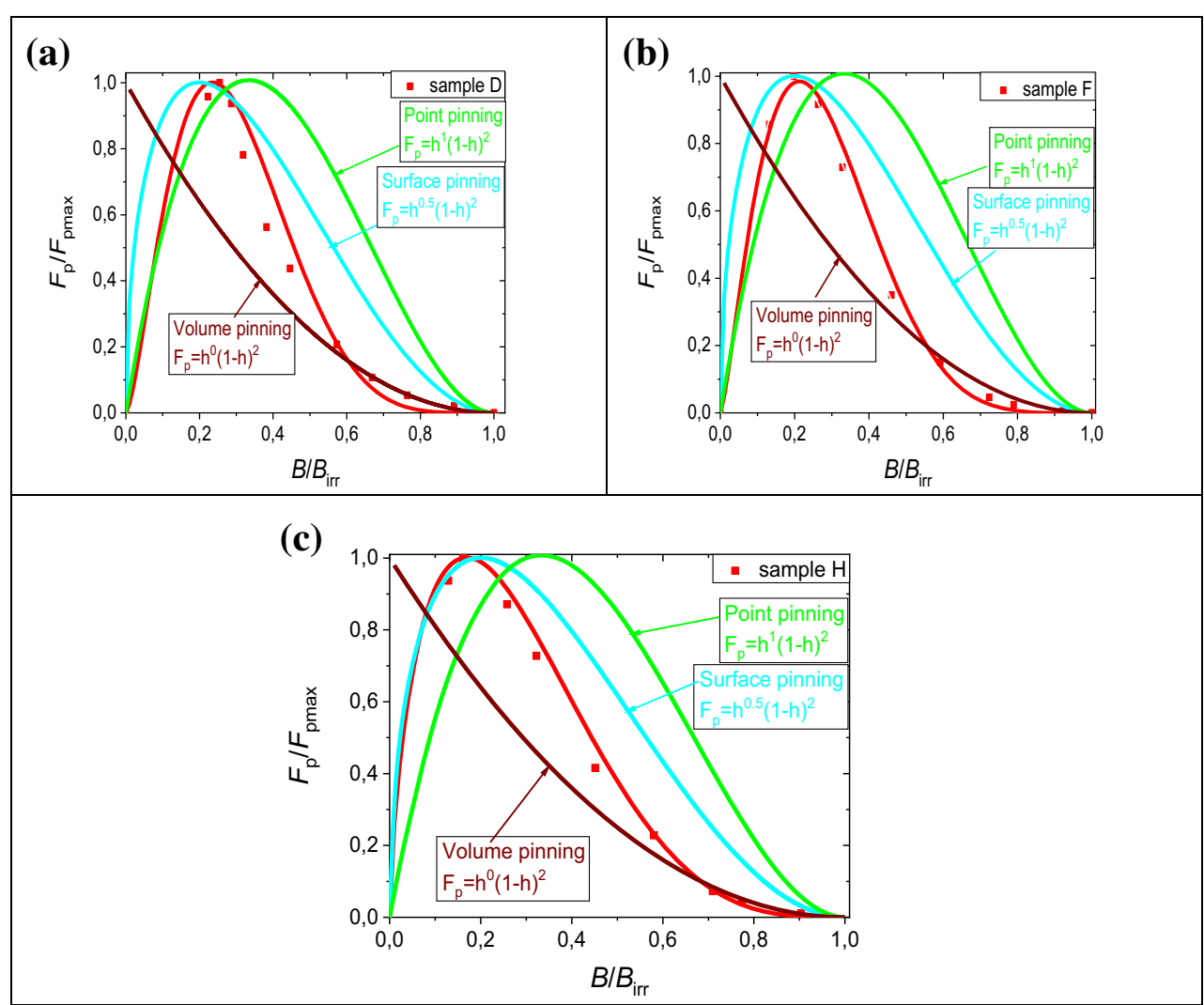

Based on the results above, multi-sectional wind-and-react coils cannot be fabricated with wires of two different diameters. For example, a low annealing temperature of the coil would produce high current density and $n$ value in the compensating coil windings and low critical current density and $n$ value in the main coil. On the other hand, a high annealing temperature would produce high critical current density and $n$ value in the main coil and low critical current density and $n$ value in the compensation coil. In both cases a homogeneous distribution of the magnetic field in the coil would not be

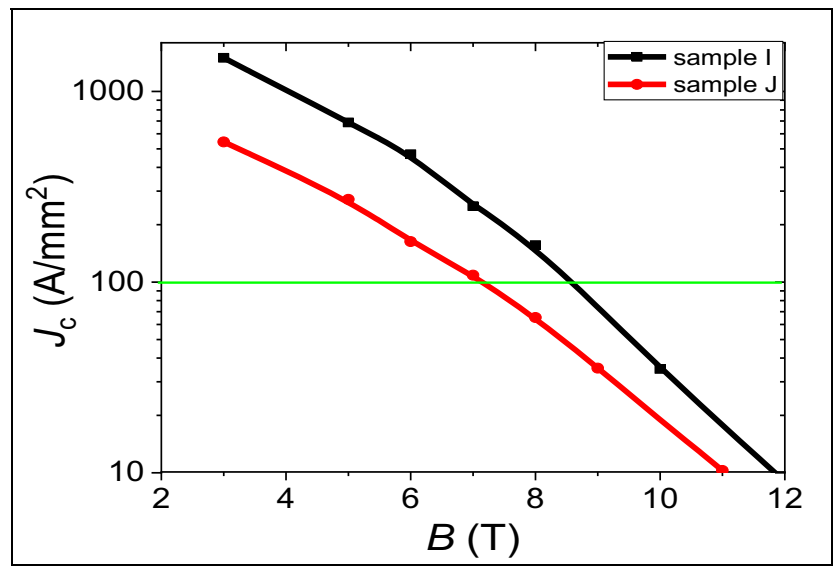

Fig. 9 Transport $J_{\mathrm{c}}-B$ curves for undoped $\mathrm{MgB}_{2}$ wires in perpendicular magnetic field for $700{ }^{\circ} \mathrm{C}$ by 60 min under $1 \mathrm{GPa}$ realized. We suggest a better method for fabricating multisectional superconducting coils. First the main coil made would be fabricated with unreacted wires of large diameter and annealed at a high temperature for producing high $J_{\mathrm{c}}$ and $n$ value. Secondly, the compensating windings would be wound to the main coil and the combined coil set. These combined coil set will heat treated at a low temperature (e.g. $570{ }^{\circ} \mathrm{C}$ [35]) for producing high $J_{\mathrm{c}}$ and $n$ value in the compensation coils. The low annealing temperature would not

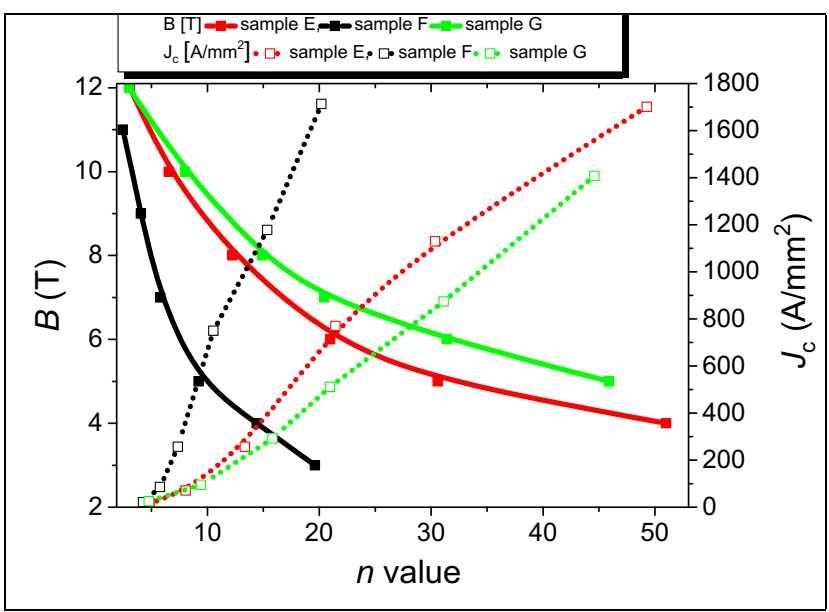

Fig. 10 The $n$ value dependency for undoped $\mathrm{MgB}_{2}$ wires. The sample $\mathrm{E}$, $0.84 \mathrm{~mm}$ at $700{ }^{\circ} \mathrm{C}$; the sample $\mathrm{F}, 0.64 \mathrm{~mm}$ at $700{ }^{\circ} \mathrm{C}$; the sample $\mathrm{G}$, $0.84 \mathrm{~mm}$ at $730{ }^{\circ} \mathrm{C}$ 
adversely affect the critical parameters of the main coil, because the already-formed ex situ $\mathrm{MgB}_{2}$ material has the high melting point above $900{ }^{\circ} \mathrm{C}[36]$.

\section{The Conclusions}

Our research shows that the rate of reaction in undoped $\mathrm{MgB}_{2}$ wires with $0.64 \mathrm{~mm}$ diameter is faster than the reaction rate in undoped $\mathrm{MgB}_{2}$ wires with $0.84 \mathrm{~mm}$ diameter. The faster reaction rates are associated with thinner $\mathrm{Mg}$ grains and high isostatic pressure during heat treatment. Moreover, low annealing temperatures $\left(650^{\circ} \mathrm{C}\right)$ for 0.64 -mm wire, high isostatic pressure, and long annealing time (60 min) yield smaller grains and voids and an increased number of connection between grains, high $\mathrm{MgB}_{2}$ material density, very high $J_{\mathrm{c}}$ of $1000 \mathrm{~A} / \mathrm{mm}^{2}$ at $6 \mathrm{~T}, J_{\text {ec }}$ of $100 \mathrm{~A} / \mathrm{mm}^{2}$ at $7 \mathrm{~T}, B_{\text {irr }}, F_{\mathrm{p}}$ high $n$ values, and point dominant pinning mechanism. On the other hand, high annealing temperature $\left(730^{\circ} \mathrm{C}\right)$ with high pressure and short annealing time $(15 \mathrm{~min})$ produces large grains and voids; reduces the number of connections between grains; reduces the uniformity and density of the $\mathrm{MgB}_{2}$ material; and decreases $J_{\mathrm{c}}\left(1000 \mathrm{~A} / \mathrm{mm}^{2}\right.$ at $4 \mathrm{~T}$ with $J_{\mathrm{ec}}$ of $100 \mathrm{~A} / \mathrm{mm}^{2}$ at $5 \mathrm{~T}$ ), $n$ value, $F_{\mathrm{p}}, B_{\text {irr }}$, and surface dominant pinning mechanism. Critical parameters including $n$ value are reduced in $0.84-\mathrm{mm}$ wires with low annealing temperature and high isostatic pressure. However, a high annealing temperature significantly increases the critical parameters of $\mathrm{MgB}_{2}$ wires sized to $0.84 \mathrm{~mm}$, suggesting that for the manufacturing of multisectional superconducting coils, the main coil should be fabricated first and should be annealed at a high temperature. The compensation coil would be fabricated after the main coil and heat treated at a low temperature, which will allow to maintain high magnetic field in both main and compensation coils. This coil manufacturing process will lead to improvements in the homogeneity of the magnetic field in multi-sectional coils. Our analysis of the relationship of $n$ value with $J_{\mathrm{c}}$ and $B$ showed that $n$ value is significantly dependent on the type of pinning centers. Point pinning centers significantly increased $n$ value in middle magnetic fields, whereas surface pinning centers significantly increased $n$ value in low magnetic fields.

Open Access This article is licensed under a Creative Commons Attribution 4.0 International License, which permits use, sharing, adaptation, distribution and reproduction in any medium or format, as long as you give appropriate credit to the original author(s) and the source, provide a link to the Creative Commons licence, and indicate if changes were made. The images or other third party material in this article are included in the article's Creative Commons licence, unless indicated otherwise in a credit line to the material. If material is not included in the article's Creative Commons licence and your intended use is not permitted by statutory regulation or exceeds the permitted use, you will need to obtain permission directly from the copyright holder. To view a copy of this licence, visit http://creativecommons.org/licenses/by/4.0/.

\section{References}

1. Uchiyama, D., Mizuno, K., Akao, T., Maeda, M., Kawakami, T., Kobayashi, H., Kubota, Y., Yasohama, K.: Fibrous structure and critical current density of $\mathrm{MgB}_{2}$ superconducting wire. Cryogenics. 47, 282-286 (2007)

2. Wanga, Q.Y., Jiao, G.F., Liu, G.Q., Xiong, X.M., Yan, S.C., Zhang, P.X., Sulpice, A., Mossang, E., Feng, Y., Yan, G.: Fabrication and properties of multifilamentary $\mathrm{MgB}_{2}$ wires by insitu powder-in-tube process. Physica C. 470, 1415-1418 (2010)

3. Gajda, D., Morawski, A., Zaleski, A.J., Häßler, W., Nenkov, K., Rindfleisch, M.A., Żuchowska, E., Gajda, G., Czujko, T., Cetner, T., Hossain, M.S.A.: The critical parameters in in-situ $\mathrm{MgB}_{2}$ wires and tapes with ex-situ $\mathrm{MgB}_{2}$ barrier after hot isostatic pressure, cold drawing, cold rolling and doping. J. Appl. Phys. 117, 173908 (2015)

4. Mroczek, Z., Morawski, A., Czujko, T., Karaboğa, F., Akdoğan, M., Zaleski, A.J., Małecka, M., Cetner, T., Yetiş, H., Gajda, D., Belenli, I.: Influence of the lamella structure and high isostatic pressure on the critical current density in in situ $\mathrm{MgB}_{2}$ wires without a barrier. J. Alloys Compd. 776, 636-645 (2019)

5. Susner, M.A., Daniels, T.W., Sumption, M.D., Rindfleisch, M.A., Thong, C.J., Collins, E.W.: Drawing induced texture and the evolution of superconductive properties with heat treatment time in powder-in-tube in situ processed $\mathrm{MgB}_{2}$ strands. Supercond. Sci. Technol. 25, 065002 (2012)

6. Hu, H.L., Feng, Y., Yan, G., Li, C.S., Xu, Z.: Investigation of $\mathrm{MgB}_{2} / \mathrm{Fe}$ wires with different diameters. Supercond. Sci. Technol. 19, 1169-1172 (2006)

7. Ghorbani, S.R., Wang, X.L., Dou, S.X., Lee, S.I.K., Hossain, M.S.A.: Flux-pinning mechanism in silicone-oil-doped $\mathrm{MgB}_{2}$. Evidence for charge-carrier mean free path fluctuation pinning. Phys. Rev. B. 78, 184502 (2008)

8. Zeng, R., Dou, S.X., Lu, L., Li, W.X., Kim, J.H., Munroe, P., Zheng, R.K., Ringer, S.P.: Thermal-strain-induced enhancement of electromagnetic properties of $\mathrm{SiC}-\mathrm{MgB}_{2}$ composites. App. Phys. Lett. 94, 042510 (2009)

9. Zhang, Y., Xu, X., Zhao, Y., Kim, J.H., Lu, C., Zhou, S.H., Dou, S.X.: Significant improvement of $J_{\mathrm{c}}$ in $\mathrm{MgB}_{2}$ bulk superconductor using ball-milled high-purity crystalline. Supercond. Sci. Technol. 21, 115004 (2008)

10. Wang, D., Ma, Y., Yu, Z., Gao, Z., Zhang, X., Watanabe, K., Mossang, E.: Strong influence of precursor on the critical current density of Fe sheathed $\mathrm{MgB}_{2}$ tape. Supercond. Sci. Technol. 20, 574-578 (2007)

11. Takahashi, M., Okada, M., Nakane, T., Kumakura, H.: The influence of magnesium grain size and ball milling time on the phase formation of $\mathrm{MgB}_{2}$ tapes. Supercond. Sci. Technol. 22, 125017 (2009)

12. Li S, Dou S. Intrinsic behaviour and properties of nanocrystalline $\mathrm{MgB}_{2}$. Studies in High Temperature Superconductors, Nova Science Publishers, Inc. (New York), chapter 5,146-157 (2006)

13. Serquis, A., Zhu, Y.T., Peterson, E.J., Coulter, J.Y., Peterson, D.E., Mueller, F.M.: Effect of lattice strain and defects on the superconductivity of $\mathrm{MgB}_{2}$. Appl. Phys. Lett. 79, 4399 (2001)

14. Gajda, D., Zaleski, A., Morawski, A., Hossain, M.S.A.: New types of high field pinning centers and pinning centers for the peak effect. Supercond. Sci. Technol. 30, 085011 (2017)

15. Li, C., Suo, H., Ma, L., Yang, L., Meda, M., Patel, D., Matsumoto, A., Kumakura, H.: Significant improvement in superconducting properties of in situ powder-in-tube $\mathrm{MgB}_{2}$ wires through anthracene doping and heat treatment optimization. Supercond. Sci. Technol. 32, 105004 (2019) 
16. Vinod, K., Abhilash Kumar, R.G., Syamaprasad, U.: Prospects for $\mathrm{MgB}_{2}$ superconductors for magnet application. Supercond. Sci. Technol. 20, R1-R13 (2007)

17. Parizh, M., Lvovsky, Y., Sumption, M.: Conductors for commercial MRI magnets beyond NbTi: requirements and challenges. Supercond. Sci. Technol. 30, 014007 (2017)

18. Ghosh, A.K.: $V-I$ transition and $n$-value of multifilamentary LTS and HTS wires and cables. Physica C. 401, 15-21 (2004)

19. Taylor, D.M.J., Hampshire, D.: Relationship between the $n$-value and critical current in $\mathrm{Nb}_{3} \mathrm{Sn}$ superconducting wires exhibiting intrinsic and extrinsic behaviour. Supercond. Sci. Technol. 18, 297$302(2005)$

20. Gajda, D., Morawski, A., Zaleski, A., Cetner, T., Małecka, M., Presz, A., Rindfleisch, M., Tomsic, M., Thong, C.J., Surdacki, P.: Comparison of critical current density in SiC-doped in situ $\mathrm{MgB}_{2}$ coils and straight wire samples processed by HIP. Supercond. Sci. Technol. 26, 115002 (2013)

21. Serquis, A., Civale, L., Hammon, D.L., Liao, X.Z., Coulter, J.Y., Zhu, Y.T., Jaime, M., Peterson, D.E., Mueller, F.M., Nesterenko, V.F., Gu, Y.: Hot isostatic pressing of powder in tube $\mathrm{MgB}_{2}$ wires. Appl. Phys. Lett. 82, 2847-2849 (2003)

22. Gajda, D., Morawski, A., Zaleski, A.J., Häßler, W., Nenkov, K., Małecka, M., Rindfleisch, M.A., Hossain, M.S.A., Tomsic, M.: Experimental research of high field pinning centers in $2 \% \mathrm{C}$ doped $\mathrm{MgB}_{2}$ wires at $20 \mathrm{~K}$ and $25 \mathrm{~K}$. J. App. Phys. 120, 113901 (2016)

23. Gajda, D., Zaleski, A., Morawski, A., Cetner, T., Thong, C.J., Rindfleisch, M.A.: Point pinning centers in $\mathrm{SiC}$ doped $\mathrm{MgB}_{2}$ wires after HIP. Supercond. Sci. Technol. 29, 115002 (2016)

24. Gajda, D., Morawski, A., Zaleski, A.J., Akdoğan, M., Yetiş, H., Karaboğa, F., Cetner, T., Belenli, I.: The influence of HIP process on critical parameters of $\mathrm{MgB}_{2} / \mathrm{Fe}$ wires with big boron grains and without barriers. J. Alloys Compd. 687, 616-622 (2016)

25. Tomsic, M., Rindfleisch, M., Yue, J., McFadden, K., Phillips, J., Sumption, M.D., Bhatia, M., Bohnenstiehl, S., Collings, E.W.: Overview of $\mathrm{MgB}_{2}$ superconductor applications. Int. J. Appl. Ceram. Techn. 4, 250 (2007)

26. Gajda, D., Morawski, A., Zaleski, A.J., Akdoğan, M., Yetiș, H., Karaboğa, F., Cetner, T., Belenli, I.: Formation of high-field pinning centers in superconducting $\mathrm{MgB}_{2}$ wires by using high hot isostatic pressure process. J. Supercond. Nov. Magn. 30, 3397 (2017)

27. Morawski, A., Cetner, T., Gajda, D., Zaleski, A.J., Häßler, W., Nenkov, K., Rindfleisch, M.A., Tomsic, M., Przysłupsk, P.:
$\mathrm{MgB}_{2}$ wire diameter reduction by hot isostatic pressing - a route for enhanced critical current density. Supercond. Sci. Technol. 31, 075008 (2018)

28. Gajda, D., Zaleski, A.J., Morawski, A., Rindfleisch, M., Thong, C., Tomsic, M.: The electric field jump - detection of damaged $\mathrm{Nb}$ barrier in $\mathrm{MgB}_{2}$ wires annealed under pressure. Supercond. Sci. Technol. 28, 115003 (2015)

29. Xu, X., Kim, J.H., Hossain, M.S.A., Park, J.S., Zhao, Y., Dou, S.X., Yeoh, W.K., Rindfleisch, M., Tomsic, M.J.: Phase transformation and superconducting properties of $\mathrm{MgB}_{2}$ using ball-milled low purity boron. J. Appl. Phys. 103, 023912 (2008)

30. Shi, Z.X., Susner, M.A., Sumption, M.D., Collings, E.W., Peng, X., Rindfleisch, M., Tomsic, M.J.: Doping effect and flux pinning mechanism of nano-SiC additions in $\mathrm{MgB}_{2}$ strands. Supercond. Sci. Technol. 24, 065015 (2011)

31. Li, G.Z., Yang, Y., Susner, M.A., Sumption, M.D., Collings, E.W.: Critical current densities and $n$-values of $\mathrm{MgB}_{2}$ strands over a wide range of temperatures and fields. Supercond. Sci. Technol. 25, 025001 (2012)

32. Yamada, H., Igarashi, M., Nemoto, Y., Yamada, Y., Tachikawa, K., Kitaguchi, H., Matsumoto, A., Kumakura, H.: Improvement of critical current properties of in situ powder-in-tube-processed $\mathrm{MgB}_{2}$ tape by hot pressing. Supercond. Sci. Technol. 23, 045030 (2010)

33. Gajda, D.: Analysis method of high-field pinning centers in NbTi wires and $\mathrm{MgB}_{2}$ wires. J. Low Temp. Phys. 194, 166-182 (2019)

34. Gajda, D., Zaleski, A.J., Morawski, A.J., Haßler, W., Nenkov, K., Rindfleisch, M.A., Hossain, M.S.A.: Pinning mechanism and engineering critical current density considerations in the design of MgB2 superconducting coils. Physica C. 570, 1353606 (2020)

35. Gajda, D., Morawski, A., Zaleski, A.J., Cetner, T., Häßler, W., Nenkov, K., Małecka, M., Rindfleisch, M.A., Tomsic, M.: Significant enhancement of the critical current of $\mathrm{MgB}_{2}$ wires through a reduction of the diameter using HIP method. Scr. Mater. 143, 77-80 (2018)

36. Fujii, H., Togano, K., Ozawa, K.: Grain coupling and critical current density in Fe-sheathed carbon-substituted $\mathrm{MgB}_{2}$ tapes fabricated through an ex situ process using chemically treated powder. Supercond. Sci. Technol. 21, 095018 (2008)

Publisher's note Springer Nature remains neutral with regard to jurisdictional claims in published maps and institutional affiliations. 